Journal of English Language Teaching and Applied Linguistics

ISSN: 2707-756X

DOI: $10.32996 /$ jeltal

Journal Homepage: www.al-kindipublisher.com/index.php/jeltal

JELTAL

\title{
An Investigation into Factors Affecting Concentration of University Students
}

\author{
Hanh Vy Le 8 (D) \\ Ho Chi Minh City University of Food Industry, Ho Chi Minh City, Vietnam
}

$\triangle$ Corresponding Author: Hanh Vy Le, E-mail: vylh@hufi.edu.vn

\section{\begin{tabular}{ll}
\hline ARTICLE INFORMATION & ABSTRACT
\end{tabular}}

Received: May 05, 2021

Accepted: June 04, 2021

Volume: 3

Issue: 6

DOI: $10.32996 /$ jeltal.2021.3.6.2

\section{KEYWORDS}

Attention span, distractions, solutions, teacher's roles, concentration, university students
Concentration is one of the most influential decisive factors in student's learning quality. The higher the student's level is, the less concentration they pay in class, especially university students. Owing to this low level of concentration ability, many lecturers find it hard to maintain their enthusiasm when teaching students from this level, and also those students find it hard to achieve the best outcome when graduating from university. For that reason, this article will provide an understanding of all the distractions that undergraduate students may have during their class. Also, the roles of a teacher will be put into a discussion so that readers as teachers from all levels can have a better and deeper look into this academic job, with the hope that they may find it useful for any of their changes later if they think it is necessary so that their learners can have better experiment with them in class. And after all the analysis, this article will suggest some good and applicable solutions that can be applied to improve the situation. Hopefully, this would advance the teaching and learning quality in the university environment.

\section{Introduction}

\subsection{Definition of attention and concentration}

Attention has been an appealing subject for many researchers for many many years. According to Kumar (2003), concentration is acquirable and is referred to the mental state in which all the senses and mind of the human are focused on a particular subject. Also, attention can also be understood as a process that "encodes language input, keeps it active in working and shortterm memory, and retrieves it from long-term memory" (Robinson, 2003, p. 631). This can be explained that if one maintains their concentration well, all the knowledge or information given to them are received well and not only they can use those to deal with the current situations and later apply it them in the long term. In addition, to understand more about attention, there are also other points of view. First, according to (Kahneman, 1973, 2011; Tomlin \& Villa, 1994), attention is generally considered as the restricted intellectual ability of oneself, which (Hlas et al. (2019) explained "one is limited in regard to how much they can pay attention to at one time" (p.2). Second, Rusmita Kurniati (2009) states that there are forms of behavior of learners which can give us a better and deeper understanding of what one's concentration is like, such as the willingness of learners to listen to teachers' explanations, perform assignments given by teachers, record important materials, view images or media used, listen to friends' opinions, answer teacher questions, and be calm in class. For (Al'Omairi \& Al Balushi, 2015), attention is a significant component of one's learning.

\subsection{Importance of attention and concentration}

Teachers always want their learners to have a high concentration in class as the closer the students' attention is, the higher learning outcome and knowledge gain the student will have. The role of attention is essentially undeniable in students' learning process. For Al'Omairi and Al Balushi (2015), attention is a significant component of one's learning. Moreover, Hariyanto (2021) once said: "If the learner is really paying attention, then the learner will follow and carry out the learning activities well". Not only attention can decide a student's participation in class, but also greatly influence their learning outcome because if there is good concentration during a lesson, students can be able to deal with ease all the questions relating to the learning materials so as to obtain good score as well as learning achievement. (Hariyanto, 2021). On the other hand, according to Hariyanto, those who paid

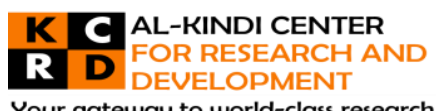

Your gateway to world-class research

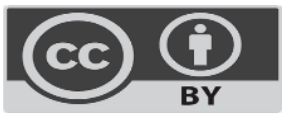

Published by Al-Kindi Center for Research and Development, United Kingdom. Copyright (c) the author(s). This open access article is distributed under a Creative Commons Attribution (CC-BY) 4.0 license 
less intention in class will struggle with receiving the following learning material, resulting in the left-behind condition and possibly feeling overwhelming and depressed with the rest of the course (2021).

\subsection{Studies on attention}

Even though the more prolonged the attention span is, the more influential the student's learning process will be (Kahneman, 1973, 2011; Tomlin \& Villa, 1994). There have been many studies conducted to prove this statement. For example, Egeth (1971) believed that a college student's focusing ability has a specific boundary through an experiment. In addition, Stuart and Rutherford (1978), through an experiment with medical students, concluded that students were at thier best concentration within the first 10 to 15 minutes of the lecture and then declined gradually until the end of the instruction. With the same goal about student's focusing limitation, Burns (1985) conducted another experiment that once again proved the maximum length of time of student's attention is around 15 minutes. So both of the mentioned studies concluded that the first 15 minutes was believed to be when students have obtained information given by the instructors.

\section{Factors affect students" attention}

A variety of factors have been considered to positively or negatively affect students' concentrating ability. So many factors, even the smallest one, can influence deeply on student's attention span, and not all of them can be controlled or adjusted by the instructors. However, there are still subjective factors that can maximize the student's concentration in class if instructors or lecturers put in many efforts. As shown in Figure 1, there are two main factors that affect attention span: internal and external factors.

Figure 1. Components of attention span span

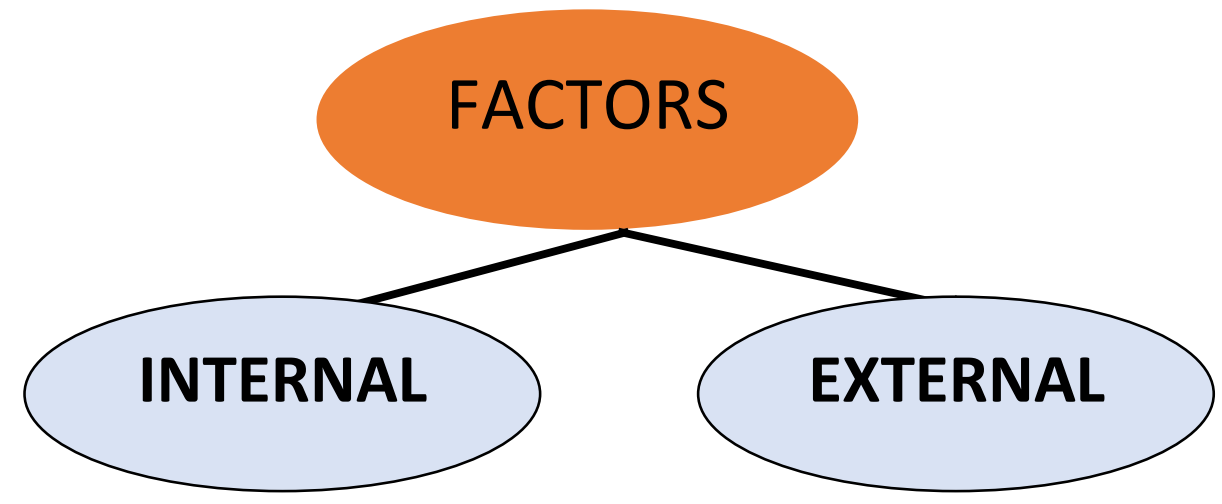

Internal factors are those within students or lecturers themselves. For example, boring is an internal factor since it is a feeling from inside oneself. It is self-created emotion. Normally, internal factors are controllable which can be changed. On the other hand, external factors are those outsides, usually out of lectures or students' ability to manage (for example, the noise of the plane taking off). Finally, teachers or lecturers can take all these internal and external factors into account to minimize distractions, improve teaching quality, and expand students' concentration level.

\subsection{Internal factors}

Students' interest and understanding ability broadly determine their concentration in class as (David et al., n.d.) once said:" Interest is the determiner of good attention, and interest is always behind the actions of an attentive student" (p.26). Students' interest is one of the internal motivations that keep them engaging effectively in class. The more passion and eagerness they have for the subject, the more curiosity and the more focus they will pay in the lesson to gain more knowledge about what they care about. And for Gerschler (2012), lesson design plays an essential part in maintaining students' interest in the class. This is to say, teachers or lecturers cannot expect students to find the dry, poor-prepared lesson to be inspired. Nonetheless, with the lesson that has more investments, more materials will maintain all the participants' concentration well and constantly attract students' attention during the whole class hours. Likewise, students' comprehension of the lesson content and lecturer's instruction during class can also cause either better focus or frustration, leading to the loss of their attention for the rest of the class. It is essential that lecturers keep track their students well so that students can be assisted in time whenever they need. Furthermore, it is also a bad situation in which students do not understand just one lesson and then they leave out all the following sections since normally all the sections relate to each other. For this reason, according to Gerschler (2012) :" it is important that the teacher ensures that students have the experience necessary to understand the lesson, and that guidance is provided when questions arise." (p.7). 
Students' physical and personal characteristics can be considered internal causes that influence attention in class. For physical aspect, for example, if students suffer from sickness, hungriness, tiredness, they will find it hard to keep their focus well throughout the whole lesson because their body and their mind are not well enough to enable them to absorb knowledge like Cicekci and Sadik (2019) confirmed through their research that students "coming to school without sleep, hungry and tired makes it difficult for them to collect their attention in the classroom (p. 19). About the characteristic aspect, students who are stubborn tend to develop their own purposes when coming to school, which is largely not about knowledge. With the different mindset, they come to class just to meet their friends, kill their spare time, play games, and do not pay much attention in class and they may also behave badly which negatively affects other students' attention.

\subsection{External factors}

While internal factors can be managed or changed, external factors are normally uncontrollable. They can be understood as objective factors around both instructors and students and greatly affect their performance during lesson time. There are countless external elements, but, in this paper, the writer would classify them into main four categories, which may assist whoever needs later to have a clear and systematic understanding of all the possible factors to come up with ways to minimize their effect.

The first is the school system itself. According to Ceicekci and Sadik (2019), it is "Education Policies and Practices". The syllabus is the first component that plays a vital role for this factor. A well-designed syllabus may prevent students from getting lost or missing in term of many important things like the course goals or objectives, marking policies, assessment and evaluating standards, homework, activities (Slattery\&Carlson, 2005). However, suppose the syllabus provided to students is poorly written. In that case, students may face vagueness in firming their goals for the course. They also get confused with what target knowledge they will gain. They cannot define which direction they should follow. They cannot make a specific plan to meet the desired expectations of both themselves and the course, so all of these lead to their less eagerness in class and consequently not have enough motivation to pay good attention in the lesson. Besides the content, the length of the syllabus itself can also lessen student's observation. The longer the duration of courses, the more impatient and boring students may show. These negative feelings will notably distract students from their gaining information process.

The second is the school or classroom environment. Raca and Dillenbourg (2013) presented a video showing that even trivial factors in class like the placement of students' seat or the utilization of visual advancements can significantly impact students' attention in class. The environment can refer to all the elements within the class. The first is classrooms' facility like the arrangement of chairs and tables, the quality of a light system, the quality of the cooling system, the modernity of assisting technology. The second is relating to students themselves, like the total number of participants in a class or the noise made by other students. For instance, if the class are too crowded, students find it is not comfortable to sit. Also, some distracting students keep doing disturbing behaviours, with the most focusing students, these factors somehow still make them find it challenging to maintain their concentration well. With the elements coming from outside the classroom environment, there are factors that interrupt students' attention, like the noise of the plane taking off, the noise of building constructions nearby, etc.

Apart from all the mentioned factors relating to student's attention during their time in class, parents' contribution is another factor that cannot be ignored. What are the family factors that can have a straightforward effect on student's concentration level? According to Betancort and Cabrera (2013), we have "parents' level of education, family size, parents' expectations about academic achievement, parents' control over the student's homework, etc" (p.171) which create a profound impact on student's academic achievement, and especially the ability to put their mind in the right in class. About the family size aspect, it is undeniable that if one family has 4 or 5 children, parents may have to deal with the cost burden and do not pay much attention to each child's learning process. For this reason, students end up finding that their parents do not have high expectation for their academic achievement, so they do not be motivated to try, which eventually leads to less ambition to participate in the course. This can be proved by the fact that most studies coincide that children's academic results worsen when the number of family members increases (Guo and VanWey 1999; Downey 1995; Martínez 2002). The family's factor seems to have a surprising connection with each other. A family with a low income tends to have less expectation for their children. However, parents who are well paid have to have a high level of education for that amount of salary, so it is predictable that they wish their children to be like them. Students who have parents with hope tend to pay more attention in class as they wish to please their parents with their sound learning achievement; their homework and knowledge are checked more frequently than those whose family condition is not ideal.

Besides family, teachers or instructors also directly influence students' performance in class. The first and most pivotal factor from instructors is their teaching method. Lecturers who insist on keeping one way of teaching easily discourage students and eventually lack interest in participating in class. In terms of teaching method, there are still many professors in universities today use instructor-centred methods to place themselves in the role of being a master of the subject matter. Also, in his paper, (Burke 
\& Ray, 2008) also showed his opinion toward the whole-class method which is also called directing method. He considered this method was not very effective since it just embraced the role of the instructor, not the students, so it is very easy for students to lose interaction with their instructor. However, this whole-class lecture is somehow a dominant teaching technique among various teaching methods since it is applied regularly by most or all college instructors, regardless of discipline, worldwide (Brown and Atkins 1988; Titsworth 2004). In addition, teachers' professional competencies, teaching handling-class techniques, and teacher's attitude are also factors that equally influence students' focus ability. The teacher who has abundant teaching experience and high educational level impress students more than others, due to their teaching experience, they are more flexible in using their skills and teaching methods in class to keep students' mind in the lesson, also with their source of knowledge, they can deal with any questions raised by students in class. We have (Rahiminia et al., 2020) conducted a study and through which readers understand that instructors' rich source of knowledge and deep understanding of teaching content and information plays an important role in controlling learners' focus and improving the quality of the teaching-learning process. And for the attitude, it is understandable that if instructors coming to class with eagerness, friendliness and make students feel they are approachable, students would feel comfortable and be more interested in class. Shah (2009) once said:" Teacher's personality in the attitudinal sense is a significant factor in teacher's behavior and it has a great impact on student's achievement" (p. 1).

\section{Solutions}

Once instructors acknowledge all the possible distractions from both inside and outside, it would be much easier to look for solutions that can minimize negative influences and maximize students' interest and understanding by using various necessary teaching strategies to take full advantage of students' lengthened attention span. The following solutions are aimed at instructors hoping that they can find new ways of teaching to improve both their and students' motivation in class. Moreover, the below solutions are given based on the author's personal experiences and hope that these will be applicable for all the instructors from different subjects.

\subsection{Increasing students' interest}

There are many reasons behind the decreasing learning's motivation for students, but the most affecting reasons are students' lack of enthusiasm in the lesson. It is pivotal that instructors help them set up the correct learning aim, which means students have good consciousness of their learning. When students know exactly what they will gain after the course and what knowledge they can apply in their reality, their enthusiasm and activeness will keep them interest for a long time.

\subsection{Teaching students appropriate level according to their competency}

Students' level should always be the basis for any lesson plans made by instructors. The level of content of the lesson should not be higher or lower than students' competency since it will easily demotivate students and make them lose their excitement for the class. The ideal lesson plan would include extra information related to students' previous lesson to extend their knowledge on the same subject. Also, the knowledge of new lesson should be selected carefully so students would not be overwhelming yet still relate to the materials they have already learned. By making connections and being selective with all the materials, students have a higher chance of understanding and grasping the lesson's content while still maintaining their attention well during class.

\subsection{Giving clear instructions}

All the instructions in class should be presented in a way that all the students in the class can understand. Instructors should also base on the students' level to use appropriate language level, presenting speed, and gestures to make sure that instructors' intention for the lesson will be delivered fully to all the participants in the class.

\subsection{Using a variety of teaching methods and learning activities}

Instructors should avoid repeating the same teaching strategies in class. So in order to maintain students' focus in class, lessons should be conducted in "a variety of auditory, visual, and kinesthetic techniques" (Gerschler, 2012). It is not only the teaching methods. Letting students experience different learning activities is also an advisable solution to prevent boredom and inattention. If students constantly complete their assignments with different activities like group work, games, role-playing, they will feel the diversity of learning methods and be more curious about what they will do next, which will hopefully help them keep their enthusiasm and increase their information retention.

\subsection{Develop a good relationship with students and their family}

Many instructors now have a good connection with students' family, which will help them easily inform students' learning process with the parents. With the constant exchange, both parents and instructors can closely observe students' learning and make appropriate and in time interferences. Also, different students, different family problems, even though an instructor may not make so much change for the student's family circumstance, they can make the student feel cared for and empathise if the 
instructor understands and encourages them when needed. By doing this, instructors gradually develop a good relationship with students and possibly make timely encouragements and consolations to maintain the spirit and enthusiasm of the students.

\subsection{Giving feedback constantly to the school management system}

Besides focusing on teaching in class, instructors are also responsible for assuring students have the most comfortable and convenient learning environment. Whenever there are aspects broken like the light system, the cooling system, the projector, instructors should inform who is in charge of fixing the problems as soon as possible. All the problems in term of the classroom's facilities are not something to be ignored. Even though they seem trivial, they also affect students' attention in class. For example, if the projector is broken, teachers would be limited in the ways they present the lesson, students cannot see any videos, clips or presentations, this will influence not only the effectiveness of the lesson but also the eagerness of students in class.

\subsection{Improving instructor's own knowledge}

With the fast development of the world, knowledge is also constantly updated. In order to impress students and be able to deal with all of their random questions, instructors should equip themselves with a rich source of information, including both old and new ones. Not only the knowledge but also the teaching methods are the ones that should always be innovated. This will make the instructors more confident in their ability to teach and draw students' attention.

\section{Conclusion}

Maintaining student's focus is both a challenge and a motivation for teachers to change themselves if needed for the better. Even though countless factors can affect students' ability to keep their focus well, there are also solutions. Solutions have given above maybe not the best to deal with all the distractions, especially the uncontrollable ones, yet they can be one of the ways for instructors to minimize as much as possible the negative effects and maximize students' attention span. Also, instructors are advised to apply every possible way in their ability. Furthermore, instructors should not be discouraged when a method fails because as long as there is love for the profession, everything can be solved.

\section{References}

[1] Al'Omairi, T., \& Al Balushi, H. (2015). THE INFLUENCE OF PAYING ATTENTION IN CLASSROOM ON STUDENTS' ACADEMIC ACHIEVEMENT IN TERMS OF THEIR COMPREHENSION AND RECALL ABILITY. In Uslu, F (Ed.), 2ND INTERNATIONAL CONFERENCE ON EDUCATION AND SOCIAL SCIENCES (INTCESS'15) (pp. 684-693).

[2] Betancort, M., \& Cabrera, L. (2013). Family influences in academic achievement. A study of the Canary Islands FAMILY INFLUENCES IN ACADEMIC ACHIEVEMENT A study of the Canary Islands INFLUENCIAS DE LA FAMILIA EN EL RENDIMIENTO ACADÉMICO Un estudio en Canarias C armen N ieves P érez S ánchez . January. https://doi.org/10.3989/ris.2011.04.11

[3] Brown, A.G., and M. Atkins. 1988. Effective teaching in higher education. New York: Methuen.

[4] Burns, R.A. 1985. Information impact and factors affecting recall. Paper presented at Annual National Conference on Teaching Excellence and Conference of Administrators, Austin, TX, May.

[5] Burke, L. A., \& Ray, R. (2008). Re-setting the concentration levels of students in higher education: An exploratory study. Teaching in Higher Education, 13(5). https://doi.org/10.1080/13562510802334905

[6] Cicekci, M. A., \& Sadik, F. (2019). Teachers' and Students' Opinions About Students' Attention Problems During the Lesson. 8(6), 15-30. https://doi.org/10.5539/jel.v8n6p15

[7] David, J., Sánchez, B., De Córdoba, U., De Eucación Básica, F., \& Humanas, Y. C. (n.d.). PROMOTING ADHD STUDENTS' ATTENTION SPAN THROUGH LESSONS WITH DIFFERENTIATED CONTENT SYLLABUS DESIGN.

[8] Egeth, H.E. 1971. How college students attend to and ignore stimuli during learning. Washington, DC: Office of Education (DHEW) Bureau of Research.

[9] Downey, D. 1995. "When bigger is not better: family size, parental resources, and children's educational performance." American Sociological Review 60 (5): 746-761

[10] Gerschler, J. (2012). Classroom Strategies for Maintaining Student Focus. Universidad Del Papaloapan, September $2012,98$.

[11] Guo, G. and L. K. VanWey. 1999. "Sibship size and intellectual development: is the relationship causal?." American Sociological Review 64 (2): 169-187.

[12] [11] Hariyanto. (2021). Benefits Of Student Attention in The Implementation Of Learning. Turkish Journal of Computer and Mathematics Education (TURCOMAT), 12(3), 3616-3630. https://doi.org/10.17762/turcomat.v12i3.1642

[13] Hlas, A. C., Neyers, K., \& Molitor, S. (2019). Measuring student attention in the second language classroom. Language Teaching Research, 23(1), 107-125. https://doi.org/10.1177/1362168817713766

[14] Kahneman, D. (2011). Thinking, fast and slow. New York: Farrar, Straus, \& Giroux.

[15] Kumar S. (2003). An innovative method to enhance interaction during lecture sessions. Adv Physiol Educ, 27(1-4):20-5. doi: 10.1152/advan.00043.2001. [PubMed: 12594070].

[16] Martínez García, J., S. 2002. ¿Habitus o calculus? Dos intentos de explicar la dinámica de las desigualdades educativas en España con datos de la Encuesta Sociodemográfica. Madrid: UAM. 
[17] Robinson, P. (2003). Attention and memory during SLA. In C. J. Doughty \& M. H. Long (Eds.), The handbook of second language acquisition (pp. 631-678). Malden, MA : Blackwell.

[18] [3] Kahneman, D. (1973). Attention and effort. Englewood Cliffs, NJ: Prentice-Hall.

[19] Raca M, Dillenbourg P. (2013). System for assessing classroom attention. JACM. 2013:1-5. doi: 10.1145/2460296.2460351.

[20] Rahiminia, E., Yazdani, S., \& Rahiminia, H. (2020). Factors Affecting Concentration and Attendance in the Classroom from Students' Point of View in Qom University of Medical Sciences (2018). Educational Research in Medical Sciences, 8(2). https://doi.org/10.5812/erms.93075

[21] Rusmita Kurniati. (2009). Application of the Peer Teaching Method to increase the Attention of Students to the Biology Material of Class $X$ High School Students. Surakarta: FKIP UNS. Accessed from http://docs.google.com/viewer?a=v\&q=cache:VJVsD7WcPzJJ:biologi.fkip.un s.ac.id. On Sunday, 10 August 2014, 15.45 WIB.

[22] Shah, S. S. A. (2009). Impact Of Teachers Behaviour On The Academic Achievement Of University Students. Journal of College Teaching \& Learning (TLC), 6(1). https://doi.org/10.19030/tlc.v6i1.1183

[23] Slattery, J. M., \& Carlson, J. F. (2005). Preparing An Effective Syllabus: Current Best Practices. College Teaching, 53(4), $159-164$. https://doi.org/10.3200/CTCH.53.4.159-164

[24] Stuart, J., and R.J. Rutherford. 1978. Medical student concentration during lectures. The Lancet 2: 514.6.

[25] Tomlin, R.S., \& Villa, V. (1994). Attention in cognitive science and second language acquisition. Studies in Second Language Acquisition, 16, 183-203. 